\title{
www.czasopisma.pan.pl \\ The Compositions: Biodegradable Material - Synthetic Resins as Moulding Sands Binders
}

\author{
K. Major-Gabryś *, A. Grabarczyk, St.M. Dobosz \\ AGH University of Science and Technology in Cracow, Poland
}

Faculty of Foundry Engineering, Department of Moulding Materials. Mould Technology and Cast Non-Ferrous Metals,

*Corresponding author. E-mail address: katmg@agh.edu.pl

Received 17.06.2016; accepted in revised form 08.08.2016

\begin{abstract}
Growing emission requirements are forcing the foundry industry to seek new, more environmentally friendly solutions. One of the solutions may be the technologies of preparing moulding and core sands using organic biodegradable materials as binders. However, not only environmental requirements grow but also those related to the technological properties of moulding sand. Advancing automation and mechanization of the foundry industry brings new challenges related to the moulding sands. Low elasticity may cause defects during assembly of cores or moulds by the manipulators.

The paper presents the study of flexibility in the room temperature according to new method and resistance to thermal deformation of selfhardening moulding sands with furfuryl resin, containing biodegradable material PCL. The task of the new additive is to reduce the moulding sands harmfulness to the environment and increase its flexibility in the room temperature. The impact of the additive and the effect of the amount of binder on the properties of mentioned moulding sands were analysed. Studies have shown that the use of $5 \%$ of PCL does not change the nature of the thermal deformation curve, improves the bending strength of tested moulding mixtures and increases their flexibility at room temperature.
\end{abstract}

Keywords: Environment protection, Innovative foundry technologies and materials, Moulding sands, Furfuryl resin, biodegradable material.

\section{Introduction}

Organic binders based on synthetic resins can be characterized with good technological properties, but they tend to have high emission values. Therefore, modern scientific research is gradually replacing the binders derived from petrochemical raw materials with biocomposite polymers, derived from renewable sources. It is consistent with the concept of sustainable development, which is one of the priorities of European Union policy.

In the field of foundry moulding and core sands the issue of environmental impact of waste residual binding material, which are not thermally degradable, is not solved [1]. Although the amount of moulding sands stored in the landfills is getting smaller and foundries are equipped with reclamation systems, the harmfulness of the regeneration remains (binding materials) is a problem.

A new problem emerging in the moulding technology, is more and more often an insufficient capacity for elastic deformation of the moulding sands at room temperatures. The problem is particularly visible in automated foundries [2].

It therefore seems appropriate to apply to the currently used binder plasticizers, which will provide greater flexibility to the moulding and core sands. 


\subsection{Poli(e-caprolacton) - PCL as component of oil-based resins}

Literature study [3-7] proves that possibility of using biodegradable materials as additives to oil-based foundry binders to increase biodegradation of petrochemical driven substances, is possible.

Polycaprolactone (PCL), which has a compatibility with many other polymers, can be an example of mentioned additives. PCL is partly compatible or mechanically compatible with certain polymers such as polyvinyl acetate (PVAc), polystyrene (PS), polycarbonate, etc. Furthermore, PCL is compatible with other polymers such as polyvinyl chloride (PVC), akrylonitryl-styren copolymer (SAN), poly (hydroxy ether), and others alike. This feature of polycaprolactone allows to create "biodestructable" mixtures using it as the biodegradable component [5].

Preliminary studies " biodestructable " polymer blends with the use of PCL as the biodegradable component are connected with the PC polyolefin mixture system based on polyolefins such as LDPE (low density polyethylene) and PP (polypropylene). Wider research on the biodegradability of the PCL / polyolefin compound, comprising the relationship between the structure and biodegradability phase were conducted by Iwamoto and Tokiwa [8].

A further advantage of the use of an additive in the form of a biodegradable polymer PCL could be increased flexibility of the moulding material with the new two-component binder. The use of PCL as a plasticizer for plastics is well known. From a technological point of view, the use of plasticizers in polymers is very important and widely used in various industries. In 1966 the use of PCL as a plasticizer for polyvinyl chloride (PVC) has been patented. Polycaprolactone was used as a plasticizer in blends of: aliphatic polyesters, cellulose esters, aromatic polyesters, polycarbonates, polymers containing styrene (e.g. Polystyrene), polyolefins, block copolymers and NOVOLAK type resins [9-10].

The examples show a very large versatility in use of the biodegradable poly ( $\varepsilon$-caprolactone) as a component of various compositions. They also show that it is a polymer compatible with many different materials.

\section{Research}

The aim of the research is to develop new polymeric compositions as binders for foundry moulding sands.

The new multi-component binders containing widely used industrial resins and additives in the form of biodegradable polymers could demonstrate a lower harmfulness to the environment, both in foundry and reclamation processes. Ongoing research aims to develop polymer compositions that do not differ in technological properties from the currently used resins, however, which are much more environmentally friendly.

Investigation carried out in the presented work used a biodegradable poly (caprolactone $\varepsilon$ ) as an ingredient in commonly used phenol-furfuryl casting binder.

Following materials were chosen for test:

$>$ Furfuryl resin,
During the study a furan resin from Hüttenes-Albertus company under the name of Kaltharz XA20 was used. This resin does not contain nitrogen, and the free formaldehyde content is in the range of $0.05-0.15 \%$. The amount of furfuryl alcohol is $78 \%$. An aqueous solution of paratoluenesulfonic acid from the same company was used as hardener, with the trade name Aktivator $100 \mathrm{~T} 3$.

$>$ policaprolacton (PCL) - a biodegradable plasticizer,

Powdered policaprolactone (PCL) from Polysciences, Inc. Was used as both a biodegradable additive and a plasticiser. It is a biodegradable polymer with a hydroxyl end group [10].

Technical data:

CAS no: 24980-41-4

Chemical formula: $\left[-\mathrm{O}\left(\mathrm{CH}_{2}\right)_{5} \mathrm{CO}-\right]_{\mathrm{n}}$

Molecular weight: 50,000

Melting point: $58-60^{\circ} \mathrm{C}$

Selection of these materials was driver by the fact that PCL can be dissolved in the Kaltharz XA20 resin. There is therefore no need for any additional solvents to dissolve the biodegradable polymer [10].

Earlier work of authors [10-12] have shown that the polycaprolactone as an additive to moulding sands with Kaltharz XA20 furan resin in an amount of 0.055 parts per weight $(5 \%$ of the weight of the binder), and as a component of the binder replacing $5-15 \%$ of the resin amount in the binder, does not affect the thermal degradation process of investigated moulding sands [10-12]. Studies have also shown that the use of PCL added in the amount of $5 \%$ by weight of the binder does not substantially affect the mechanical properties of moulding sands with furan resin. Increasing of the share of polycaprolactone in the binder up to $15 \%$ by weight has deteriorated strength of the tested moulding sands, and resulted in an increase in their grindability [10-12].

In the context of this article the effect of addition of PCL on thermal deformation (distortion parameter hot) and bending strength of molding furan resin and the "flexibility" at room temperature was tested. The study of the "flexibility" of the moulding sands is a relatively new issue and is a response to the emerging problems of excessive fragility of moulding sands and cracking of cores, especially observed in automated production [13-14].

Following moulding sands were tested:

$\begin{array}{ll}\text { Quarto sand } & 100 \mathrm{ppw} \\ \text { Kaltharz XA20 resin } & 1,045-1,1 \mathrm{ppw}(95-100 \%) \\ \text { Aktivator 100T3 } & 0,55 \mathrm{ppw} \\ \text { PCL } & 0-0,055 \mathrm{ppw}(0-100 \%)\end{array}$

The studies included both moulding sands in which part of the binder is replaced by the new additive (Fig. 95\% F + 5\% PCL) and moulding sands into which the PCL was introduced as an additional part of the binder (Fig. \% $100 \mathrm{~F}+5 \%$ PCL). Results of this study are shown in Figures $1-4$. 


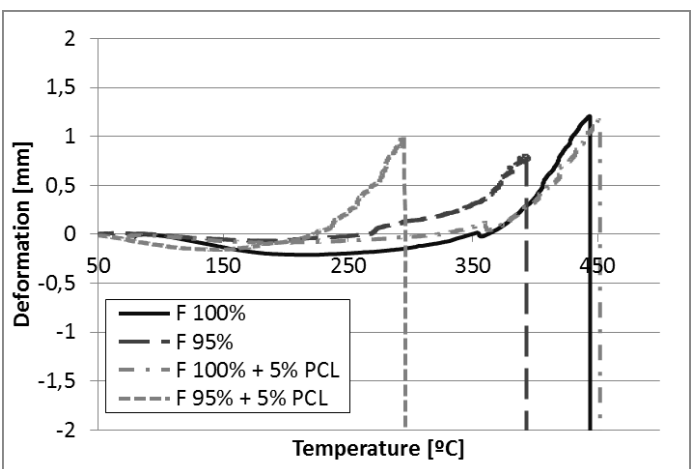

Fig. 1. Influence of PCL on thermal deformation (hot distortion parameter) of moulding sands with furfuryl resin (deformation as a function of temperature)

Studies of thermal deformation of moulding sands (hot distortion parameter) showed that the addition of the PCL biomaterial does not affect the nature of the distortion curve in moulding sands with furan resin. Thermal deformation of moulding sands as a function of temperature has a typical course of intense increase in deformation of the sample and its sudden collapse. Reducing the amount of resin to $95 \%$ in the new binder resulted in lower temperature of the specimens destruction (approx. $300^{\circ} \mathrm{C}$ ), which is even more apparent in moulding sands with reduced resin content and addition of PCL (approx. $200^{\circ} \mathrm{C}$ ) (Fig. 1). If the case of this particular moulding sand any effect of the new additive on the time after which the specimen is destroyed (approx. $70 \mathrm{sec}$ ) was not observed (Fig. 2). The moulding sand with reduced amount of binder can be characterized with the longest time necessary for destruction (approx. $92 \mathrm{sec}$ ).

Tests of bending strength of the moulding mixtures (Fig. 3) showed that the reduction of the binder content by weight to $95 \%$ decreases the strength by approx. 20\%. An additional introduction of $5 \%$ PCL to the binder (F $100 \%+5 \%$ PCL) increases the strength of the moulding sand by approx. $17 \%$. Replacing a part of the binder with the new additive $(\mathrm{F}+95 \% 5 \% \mathrm{PCL})$ resulted in reduced strength of the moulding sand in relation to the initial moulding mixture (F $100 \%$ ) by less than $3 \%$, which is within the range of measurement error.

Researched "flexibility/elasticity" of the moulding sands at ambient temperature (Fig. 4) carried out in accordance with the methodology outlined in the earlier works $[10,13]$ have shown that moulding sands with PCL addition to the binder are more flexible compared to the same moulding mixtures without the additive. The deformation of the moulding sands without PCL reached approx. $0.25 \mathrm{~mm}$ at a force of approx. $150 \mathrm{~N}$ - moulding sand F $100 \%$ and $130 \mathrm{~N}-\mathrm{F} 95 \%$ moulding sand, while the introduction of PCL to the original moulding sand composition $(100 \% \mathrm{~F})$ increases the strain up to $0.28 \mathrm{~mm}$ at a force of approx. $170 \mathrm{~N}$. the replacement of a part of the binder with PCL $(95 \% \mathrm{~F}+$ $5 \%$ PCL) increases the deformation of the moulding sand to approx. $0.32 \mathrm{~mm}$ occurring at a force of approx. $150 \mathrm{~N}$ (approx. $30 \%$ - growth as compared to original composition of the moulding sand).

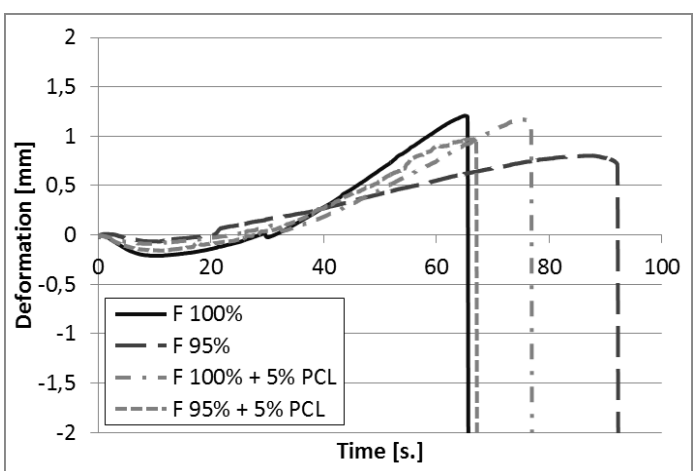

Fig. 2. Influence of PCL on thermal deformation (hot distortion parameter) of moulding sands with furfuryl resin (deformation as a function of time)

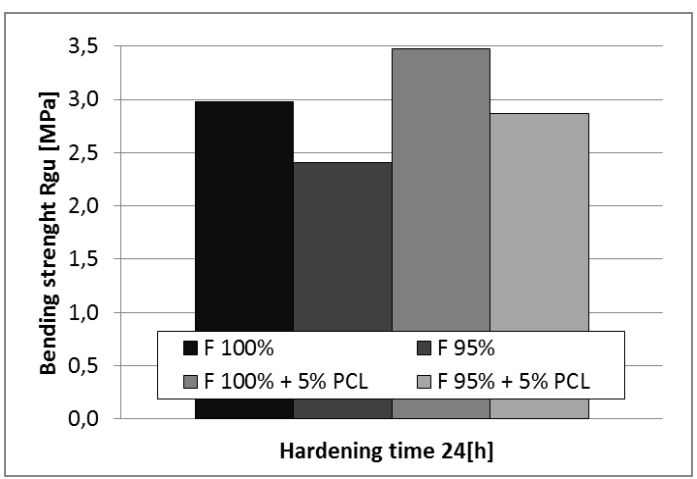

Fig. 3. Influence of PCL on bending strength of moulding sands with furfuryl resin

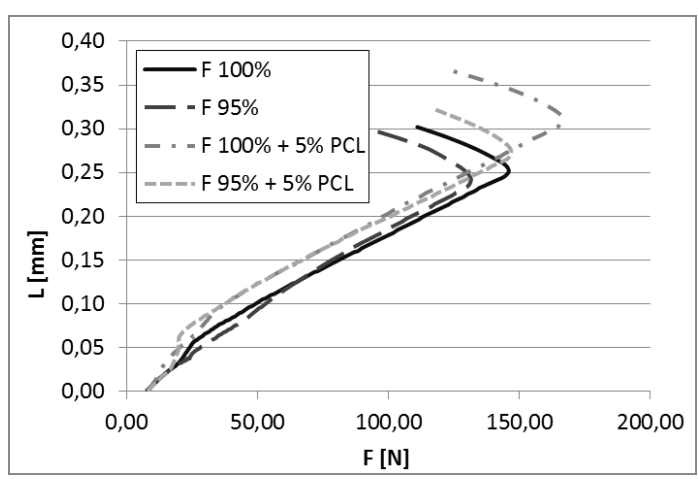

Fig. 4. Influence of PCL on "flexibility" of moulding sands with furfuryl resin in room temperature

\section{Conclusions}

Based on the analysis of literature data and presented research the following conclusions can be drawn:

- There exists a possibility of applying biodegradable materials such as PCL as a component of moulding and core sands with furfuryl resin binders. 
- $\quad$ The investigated amount of PCL addition does not change the curve of thermal deformation of tested moulding sands.

- $\quad$ Replacing a part of the binder with PCL does not affect the bending strength of the tested moulding sands, and the introduction of additional amount of PCL increases the moulding sands bending strength.

- The addition of PCL increases the "flexibility/elasticity" of tested moulding sands.

The studies will be continued, particularly in the field of the impact of the new additive to the biodegradability of the moulding sands.

\section{Acknowledgements}

The research was financed by AGH Research Project No 15.11.170.568

\section{References}

[1] Holtzer, M. (2001). Waste and by-products in foundries. Kraków: Uczelniane Wydawnictwa Naukowo-Dydaktyczne, AGH. (in Polish).

[2] Gröning, P., Schreckenberg, S. \& Jenrich, K. (2015). Herstellung von hochkomplexen Zylinderkurbelgehäusen, Giessere. 10(01), 42-47.

[3] Choi, E.-J. \& Park, J.-K. (1996). Study on biodegradability of PCL/SAN blend using composting method, Polymer Degradation and Stability. 52, 321-326.
[4] Scott, G. (2001). Environmentally degradable polyolefins: When, why and how, Expert Group Meeting on Environmentally Degradable Plastics, Present Status and Perspectives, Trieste: ICS-UNIDO, 37-48.

[5] Scott, G. (2000). Green Polymers. Polymer Degradation and Stability. 68, 1-7.

[6] Wiles. D.M. \& Scott. G. (2006). Polyolefins with Controlled Environmental Biodegradability. Polymer Degradation and Stability. 91, 1581-1592.

[7] Shah, A.A., Hasan, F., Hameed, A. \& Ahmed, S. (2008). Biological Degradation of Plastics: A Comprehensive Review. Biotechnology Advances. 26, 246-265.

[8] Iwamoto, A. \& Tokiwa, Y. (1994). Enzymatic degradation of plastics containing polycaprolactone. Polymer Degradation and Stability. 45(2), 205-213.

[9] Eastmond. G.C. (2000). Poly( $\varepsilon$-caprolactone) Blends, Advances in Polymer Science. 149, 59-222.

[10] Major-Gabryś, K. (2016). Foundry molding sand and core environmentally friendly. Katowice: Archives of Foundry Engineering, Komisja Odlewnictwa PAN. ISBN 978-8363605-13-1. (in Polish).

[11] Major-Gabryś, K., Dobosz, St.M., Drożyński, D. ～\& Jakubski, J. (2015). The compositions: biodegradable material - typical resin, as moulding sands' binders. Archives of Foundry Engineering. 15(1), 35-40.

[12] Major-Gabryś, K., Grabarczyk, A., Dobosz, St.M. \& Jakubski, J. (2016). New Bicomponent Binders for Foundry Moulding Sands. Metalurgija. 55(3), 385-387.

[13] Grabarczyk, A., Major-Gabryś, K., Dobosz, St.M., Jakubski, J. \& Morek, J. (2015). Flexibility - a new criterion for assessing the quality of molding. Archives of Foundry Engineering.15(4), 39-42. 